\title{
PERANCANGAN REPOSITORY DENGAN DUKUNGAN OPEN ARCHIEVE INITIATIVE (OAI) BERBASIS OPEN SOURCE MENGGUNAKAN CODEIGNITER DAN NODE.JS
}

\author{
Taufiq Iqbal ${ }^{1}$, Bahruni $^{2}$ \\ E-mail: taufiqiqbal@amikindonesia.ac.id, bahruni@amikindonesia.ac.id \\ D-III Manajemen Informatika AMIK Indonesia \\ L. Teuku Nyak Arif, Simpang Krueng Raya, Banda Aceh, Aceh. Tlpn/ Fax : (0651) 52043
}

\begin{abstract}
Abstrak
Repository menjadi sarana yang baik untuk mempublikasikan hasil penelitian pada lingkup yang lebih luas. Hal ini diharapkan dapat meningkatkan reputasi yang baik untuk referensi dari para penulis dalam pengembangan ilmu pengetahuan. Repository merupakan sebuah perangkat lunak open source yang dapat digunakan sebagai arsip serta dapat menyimpan gambar, data penelitian dan suara dalam bentuk digital. Tersebarnya repository seperti; e-prints, dspace, fedora, greenstone digital library, ganesa digital library (GDL) dan SLIMs tetapi masih kurang banyak digunakan oleh Perguruan Tinggi di Indonesia dikarenakan hal teknis spesifikasi serta kesulitan masalah biaya dan sumber daya. Penelitian ini mencoba untuk membangun model repository yang dapat digunakan sebagai bentuk manajemen publikasi dan penerbitan serta memiliki fitur Open Archieve Initiative (OAI) dan penanganan metadata agar dapat secara baik ter-index pada indexing internasional dan bersifat open source. Secara garis besar penelitian ini dibagi dalam tiga tahapan, yaitu pengumpulan data pra pengembangan, pengembangan serta implementasi, dan pengumpulan data pasca pengembangan. Pengumpulan data pra pengembangan dimaksudkan untuk mendapatkan bekal studi pendahuluan tentang inti masalah yang sedang dihadapi, sedangkan tahap pengembangan dan implementasi berfokus pada memodelkan perancangan perangkat lunak ke dalam diagram dan membuat kode pemrograman untuk mengimplementasikan perancangan yang telah dibuat. Sedangkan tahapan pengumpulan data pasca pengembangan adalah untuk pembenahan aplikasi yang dibuat, penarikan kesimpulan, dan saran untuk topik penelitian selanjutnya. Dari hasil penelitian maka dapat disimpulkan bahwa repository dibangun dengan framework codeigniter, node.js dan menggunakan bahasa pemograman pendukung seperti HTML, CSS, Jquery, Java Script, JSON, AJAX, Boostrap sebagai media dalam perancangan antar muka. Sedangkan PHP sebagai server side dan MySQL sebagai database. Aplikasi repository ini diberi nama dengan "T-REPOSITORY" yang dapat di unduh pada sosial coding github.
\end{abstract}

Kata kunci : Repository; Open Archieve Initiative (OAI); Open source, Codeigniter, Node.js

\section{Pendahuluan}

Seiring dengan Undang-Undang Republik Indonesia Nomor 12 Tahun 2012 Tentang Pendidikan Tinggi yang mewajibkan Perguruan Tinggi untuk publikasi ilmiah sebagai salah satu sumber belajar dan untuk pengembangan budaya akademik serta pembudayaan kegiatan baca tulis bagi Sivitas Akademika, sehingga dapat mendorong dosen dan anak didik agar lebih produktif dalam menghasilkan publikasi ilmiah sehingga dapat meningkatkan daya saing bangsa Indonesia di tingkat dunia dalam hal publikasi. Publikasi dalam bentuk daring menjadikan popularitas dan trend sendiri dalam persaingan di dunia pendidikan tinggi saat ini, kesiapan Perguruan Tinggi diuji dengan teknologi daring sebagai salah satu syarat dalam akreditasi kampus.

Repository menjadi sarana yang baik untuk mempublikasikan hasil penelitian pada lingkup yang lebih luas (Bienert et al, 2016). Hal ini diharapkan dapat meningkatkan reputasi yang baik untuk referensi dari para penulis dalam pengembangan ilmu pengetahuan. Repository merupakan sebuah perangkat lunak open source yang dapat digunakan sebagai arsip serta dapat menyimpan gambar, data penelitian dan suara dalam bentuk digital (Teredesai et al, 2019). Banyaknya repository yang tersebar seperti; eprints, d-space, fedora, greenstone digital library, ganesa digital library (GDL) dan SLIMs menjadi alternatif sendiri dalam memilih repository yang ingin digunakan (Arnomo, 2018). Tetapi masih terdapat beberapa kekurangan seperti dibutuhkan server tersendiri untuk memuat data publikasi, dimana kebanyakan Perguruan Tinggi masih kesulitan masalah biaya dan sumber daya. Tujuan khusus penelitian antara lain untuk:

a) Ingin membuktikan teori-teori yang ada terhadap arsitektur repository dan digital library untuk disesuaikan dengan perkembangan pengetahuan dan teknologi saat ini dengan menggunakan model Big Data serta menggunakan Open Archieve Initiative (OAI).

b) Merancang suatu repository baru untuk memudahkan Perguruan Tinggi untuk publikasi daring sesuai kebutuhan, sehingga 
keterbatasan pengguna pada manajemen penerbitan menjadi komplek.

c) Mengembangkan hasil penelitian yang sudah ada, yaitu mengembangkan repository yang lebih fleksibel dibandingkan dengan repository dan digital library yang sudah ada.

Selama ini pengembangan repository telah banyak dilakukan tetapi masih dalam Analisa repository yang dibangun oleh pihak lain (negara lain), selain itu penggunaan software repository yang komplek dan membutuhkan arsitektur yang mahal. Penelitian ini sangat dibutuhkan agar nantinya hasil penelitian dapat mengembangan arsitektur repository merupakan suatu teknologi baru yang lebih baik dan efisien dan dapat digunakan oleh Perguruan Tinggi di Indonesia khususnya AMIK Indonesia.

Pemanfaatan teknologi dalam pengembangan perangkat lunak memberi kesempatan kepada peneliti untuk membangun aplikasi dan mengetahui efektifitasnya dalam proses pembuatan repository yang bersifat open source. Selain itu, dengan meningkatnya perkembangan teknologi khususnya pada pengembangan perangkat lunak, memicu penelitian mengenai layanan dan aplikasi untuk repository dengan berbagai fitur layanan manajemen penerbitan secara daring.

Pengembangan digital library juga dilakukan oleh Agosti, Ferro, dan Silvello (2016). Dalam hal ini, penelitian ini merancang ontologi yang memungkinkan untuk memodelkan dan memetakan konsep tingkat tinggi baik dari model 5S (Streams, Structures, Spaces, Scenarios, Societies) dan Model DELOS Reference. Penelitian ini menyediakan ontologi rinci untuk semua domain dari model tersebut, yaitu pengguna, konten, fungsionalitas, kualitas, kebijakan, dan domain komponen arsitektur untuk menyediakan alat yang bekerja untuk membuat Digital Library System (DLS) beroperasi bersama pada tingkat abstraksi yang tinggi. Namun, penelitian ini masih menghasilkan suatu konsep menggambarkan interoperabilitas yang dicapai antara model Referensi 5S dan DELOS.

Selain itu, penelitian juga dilakukan oleh Rossi dan Ahmed (2016). Penelitian ini bertujuan untuk kami meninjau kembali desain repository saat ini dan penyimpanan data interaktif, yang tidak hanya membuat data dapat diakses, tetapi juga menyediakan teknik untuk eksplorasi data interaktif, mining, dan visualisasi dengan cara yang mudah, intuitif, dan mengalir bebas.
Morgado., et al (2018) dalam jurnal yang berjudul Adaptation of Descriptive Metadata for Managing Educational Resources in the GREDOS Repository melakukan penelitian untuk mempelajari pemetaan metadata yang diperlukan untuk beradaptasi dari Learning Object Metadata (LOM) ke Qualified Dublin Core yang merupakan standar yang digunakan dalam repositori GREDOS di Salamanca University yang dibangun dengan platform DSpace. Hasil penelitian menyajikan pelaksanaan Learning Object Description (LOD) pada repositori GREDOS.

Lain halnya dengan Roy, Biswas, dan Mukhopadhyay (2016) yang melakukan penelitian terhadap Open Access Repository pada Universitas India dengan Multilingual Framework. Penelitian ini mengusulkan model open access repository (OAR) berdasarkan prototipe BURA (Burdwan University Research Archive) untuk universitas India dengan beberapa fitur utamanya, selanjutnya penelitian ini menjelaskan penggabungan dan integrasi dari sistem akses subjek berbasis skrip berbasis web standar dalam kerangka kerja OAR serta melakukan pengembangan antarmuka Unicodecompliant berbasis Bengali script-based yang mendukung penelusuran terpadu sumber daya berbasis bahasa Bengali.

Penelitian ini berbeda dengan penelitian terkait seperti diatas, dimana penelitian ini mencoba untuk membangun model repository yang dapat digunakan sebagai bentuk manajemen publikasi dan penerbitan serta memiliki fitur Open Archieve Initiative (OAI) dan penanganan metadata agar dapat secara baik ter-index pada indexing internasional. Aplikasi tersebut memungkinkan pembaharuan data/konten dan sharing dari berbagai sumber digital online. Repository dapat memungkinkan pengguna end user, serta tetap mengacu pada standar manajemen pengelola terbitan internasional. Diharapkan dengan adanya repository dapat meningkatkan publikasi dan manajemen penerbitan secara elektronik serta sepenuhnya dilaksanakan baik oleh penulis, penerbit maupun Perguruan Tinggi lainnya. Aplikasi Repository yang penulis bangun menggunakan Codeigniter dan node.js.

\section{Metode Penelitian}

a. Rancangan Penelitian

Secara garis besar penelitian ini dibagi dalam tiga tahapan, yaitu pengumpulan data pra pengembangan, pengembangan serta implementasi, dan pengumpulan data pasca 
pengembangan. Pengumpulan data pra pengembangan dimaksudkan untuk mendapatkan bekal studi pendahuluan tentang inti masalah yang sedang dihadapi, sedangkan tahap pengembangan dan implementasi berfokus pada memodelkan perancangan perangkat lunak ke dalam diagram dan membuat kode pemrograman untuk mengimplementasikan perancangan yang telah dibuat. Sedangkan tahapan pengumpulan data pasca pengembangan adalah untuk pembenahan aplikasi yang dibuat, penarikan kesimpulan, dan saran untuk topik penelitian selanjutnya. Metode perancangan yang digunakan adalah metode air terjun (waterfall).

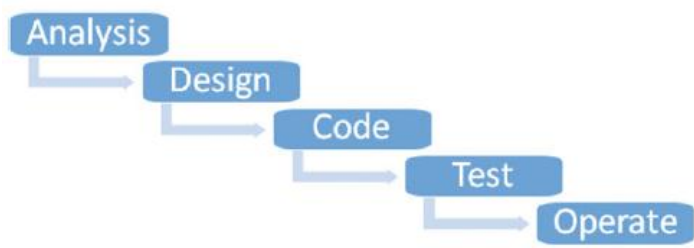

Gambar 1. Metode Waterfall

\section{b. Lokasi Penelitian}

Penelitian ini secara pokok akan dilaksanakan pada Laboratorium Rekayasa Perangkat Lunak AMIK Indonesia Banda Aceh. Pada laboratorium tersebut terdapat komputer yang dapat digunakan untuk mengembangkan perangkat lunak repository pada berbagai sistem operasi khususnya Big Data. Selain itu, penelitian ini juga akan melibatkan mahasiswa dan pengelola perpustakaan di luar lab untuk melakukan uji coba aplikasi yang dibuat.

\section{c. Model Penelitian}

Model penelitian yang digunakan adalah penelitian kualitatif, artinya data yang dikumpulkan dan digunakan untuk penelitian bukan merupakan data statistik. Dalam penelitian kualitatif, data yang diolah adalah berupa kata-kata yang dikumpulkan dengan metode wawancara atau diskusi kelompok. Metode ini banyak digunakan untuk pengembangan perangkat lunak karena dapat menghasilkan data kebutuhan sistem yang lebih deskriptif dan mudah diimplementasikan ke dalam perangkat lunak.

\section{d. Teknik Pengumpulan dan Analisis Data \\ Data yang dikumpulkan dalam penelitian kualitatif adalah data tekstual berupa kata dan kalimat. Cara yang paling banyak}

digunakan untuk pengumpulan data kualitatif dalam penelitian ini adalah dengan melalui studi literatur dan diskusi kelompok. Pada penelitian ini pengumpulan data awal yang digunakan untuk mendapatkan daftar kebutuhan sistem adalah dengan melakukan studi literatur tentang repository, bahasa pemrograman, dan big data. Selanjutnya data studi literatur di-list untuk dianalisis antara standard Repository yang ingin dicapai dan repository yang sudah ada saat ini. Selanjutnya dilakukan juga studi dokumentasi repository dan analisis pola pengembangan komponen tambahan (plugin) yang dapat diakomodasi oleh repository. Ini diperlukan untuk menentukan strategi komunikasi antara repository dan pihak pengembang perangkat lunak yang akan dikembangkan pada sistem operasi big data.

Sedangkan pengumpulan data akhir setelah proses implementasi akan dilakukan dengan cara membuat checklist fitur yang direncanakan dan yang telah dipenuhi, serta uji performa untuk mendapatkan data kebutuhan perangkat keras implementasi sistem. Kemudian purwarupa diuji cobakan kepada mahasiswa dan penerbit jurnal untuk mendapatkan feedback dalam bentuk kuisioner dan juga wawancara langsung. Hasil dari kuisioner akan diinputkan ke dalam tabulasi dan dilakukan penghitungan sederhana untuk mendapatkan data kuantitatif keberhasilan sistem. Sedangkan data hasil wawancara akan didokumentasikan dan dikategorisasikan untuk membedakan evaluasi untuk penyempurnaan program yang dapat dilakukan pada penelitian ini, atau akan dijadikan masukan pada penelitian berikutnya.

\section{Hasil dan Pembahasan}

a. Hasil perancangan sistem

Dengan penyesuaian rancangan maka didapatkan rancangan dasar pengembangan aplikasi repository yang terdiri dari rancangan masukan:

- Kategori

- Judul

- Abstrak

- Tanggal Publish

- ISSN

- ISBN

- Volume

- Penulis

- Kontributor 
- Kata Kunci

- Dokumen

- Daftar Pusaka

- User atau Admin

Sedangkan Analisa keluaran terdiri dari:

- Data repository

- Open Archives Initiative

b. Tampilan Aplikasi

Adapun hasil dari rancangan aplikasi repository sebagai berikut:

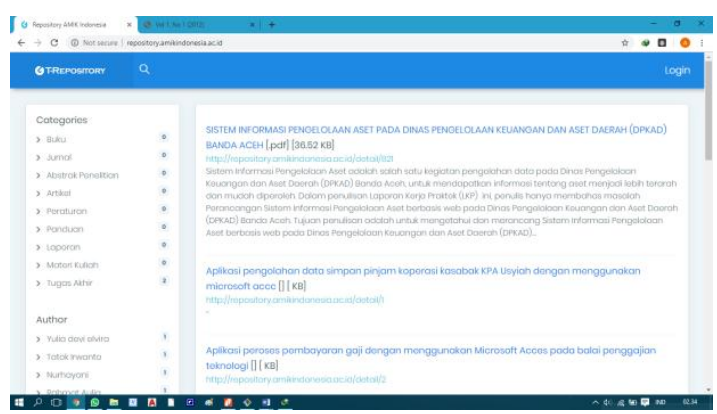

Gambar 2. Halaman Utama

Halaman Utama pertama ketika di akses, halaman ini terdiri dari informasi seperti; kategori, penulis, tahun keluaran, rss feed, OAI, pencarian, dan menampilkan data repository yang telah di input seperti; judul, file, ukuran file, link, dan abstrak. Untuk melihat secara detail informasi data repository dengan melakukan klik pada judul, seperti terlihat pada gambar 3 .

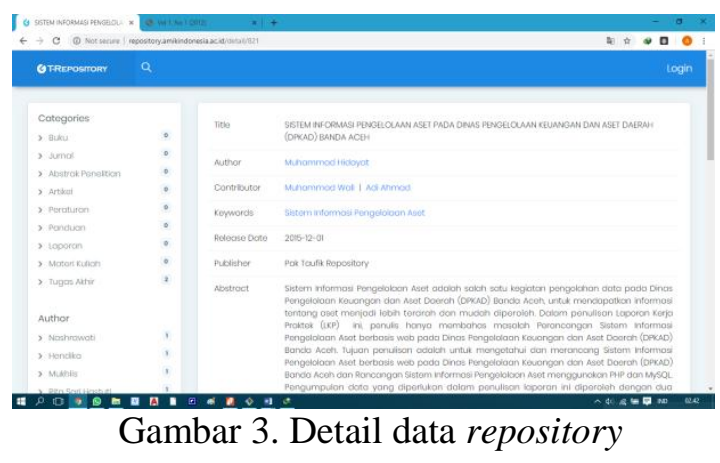

Pada detail data repositori terdiri dari; judul, penulis, kontributor, kata kunci, tanggal rilis, publish, abstrak, url, kategori, referensi, dan data file. Untuk mengakses halaman admin, pengelola repository melakukan login dan mengisi username dan password seperti pada gambar 4.

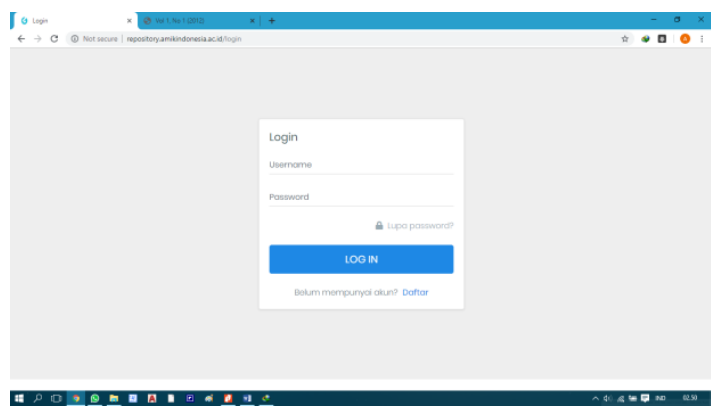

Gambar 4. Halaman login

Setelah melakukan proses login, pengelola repository akan di arahkan ke halaman admin sperti terlihat gambar 5 .

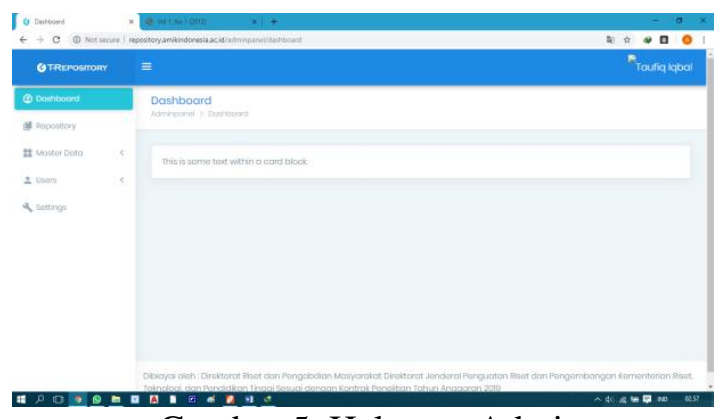

Gambar 5. Halaman Admin

Pada halaman ini terdiri informasi dalam bentuk grafik dan terdiri dari menu; dashboard, repository, master data, user, dan setting. Pada menu master data terdapat submenu kategori, sedangkan pada menu user terdiri dari submenu akun dan profil. Pada menu repositori terdapat informasi dalam bentuk daftar yang terdiri dari judul, penerbit, author, dan publish seperti terihat pada gambar 6 .

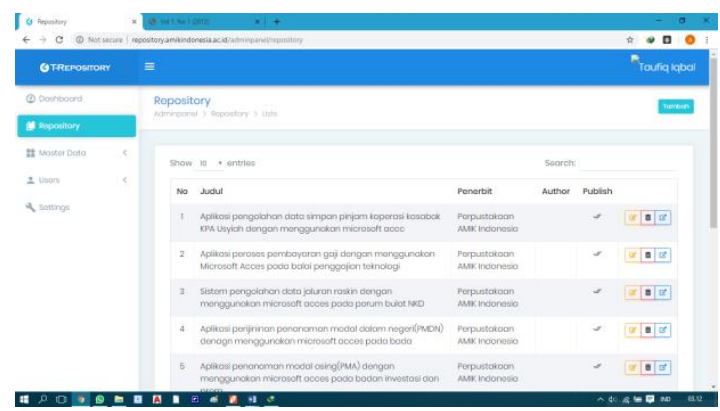

Gambar 6. Halaman Daftar Repository 
Pada halaman daftar repository pengelola dapat mengiput data seperti judul, abstrak, tanggal publish, ISSN, ISBN, volume, file, daftar pusaka, kategori, penulis, kontributor, dan kata kunci. Selanjutnya menu master data terdapat submenu kategori dimana informasi kategori ditampilkan dalam bentuk daftar dan pengelola juga dapat menambahkan nama kategori.

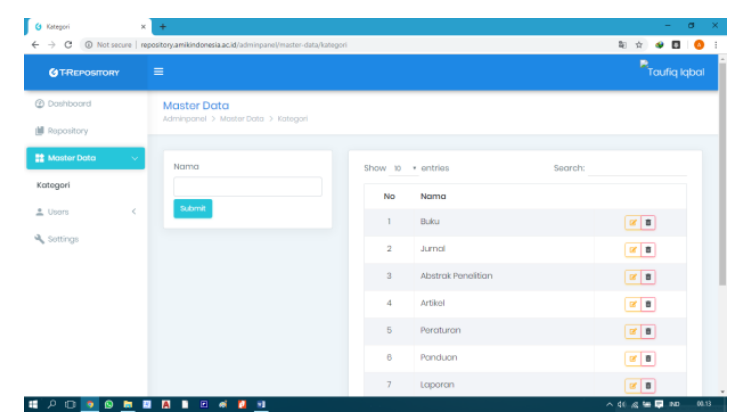

Gambar 7. Halaman Master Data

Pada halaman master data pengelola dapat menambahkan, mengedit dan menghapus di nama kategori. Pada menu users terdapat submenu account dan profil seperti terlihat digambar 8 .

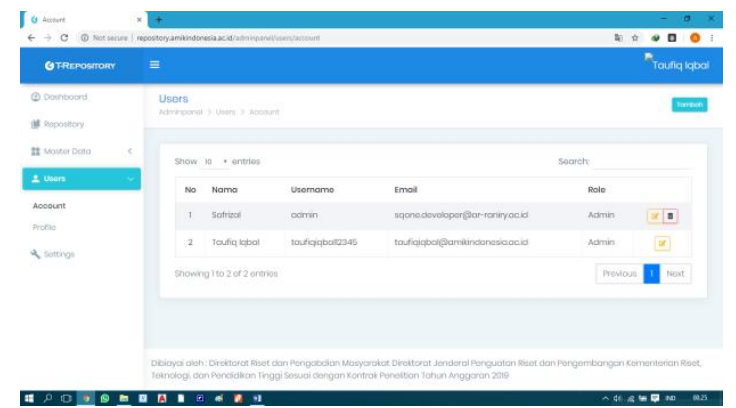

Gambar 8. Halaman Users

Pada halaman users pengelola dapat menambahkan akun operator yang memiliki akses yang sama. Selain dapat menambah akun operator, pengelola repositori dapat mengubah informasi profil pengguna terdiri dari avatar, nama lengkap, username, email, password, konfirmasi password seperti terlihat di gambar 9.

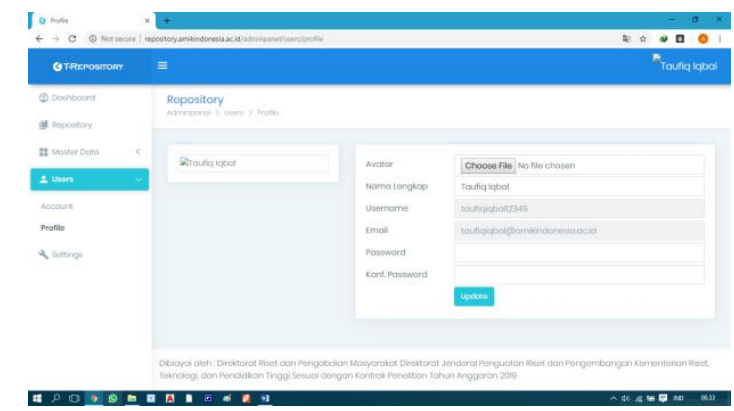

Gambar 9. Halaman Profil

Pada form selanjutnya yaitu halaman setting yang terdiri dari favicon, logo, repository name, repository email seperti terlihat digambar 10.

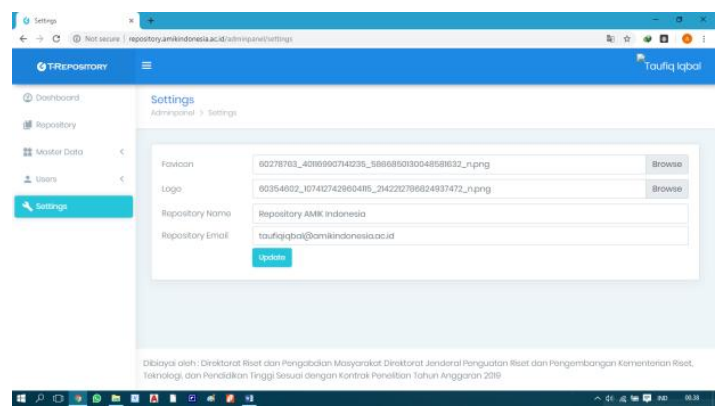

Gambar 10. Halaman setting

Pada halaman setting penggelola mengubah favico, logo, repository name, dan repository email.

\section{Kesimpulan}

Dari hasil penelitian maka dapat disimpulkan bahwa repository dibangun dengan framework codeigniter, node.js dan menggunakan bahasa pemograman pendukung seperti HTML, CSS, Jquery, Java Script, JSON, AJAX, Boostrap sebagai media dalam perancangan antar muka. Sedangkan PHP sebagai server side dan MySQL sebagai database. Aplikasi repository ini diberi nama dengan "T-REPOSITORY" yang dapat di unduh pada sosial coding github dengan url: https://github.com/taufiqiqbal/repository. 


\section{Daftar Pustaka}

[1] Agosti, M., Ferro, N. and Silvello, G., 2016. Digital library interoperability at high level of abstraction. Future Generation Computer Systems, 55, pp.129-146.

[2] Arnomo, I., 2018. Perbandingan Perangkat Lunak Repository Institusi: Studi Kasus pada Repository Institusi di Indonesia. An International Journal on Information and Communication Technology, 3(1), pp.52-56.

[3] Bienert, S., Waterhouse, A., de Beer, T.A., Tauriello, G., Studer, G., Bordoli, L. and Schwede, T., 2016. The SWISS-MODEL Repository - new features and functionality. Nucleic acids research, 45(D1), pp.D313D319.

[4] Morgado, E.M.M., Ortuño, R.A.C., Yang, L.L. and Ferreras-Fernández, T., 2018. Adaptation of Descriptive Metadata for
Managing Educational Resources in the GREDOS Repository. In Online Course Management: Concepts, Methodologies, Tools, and Applications (pp. 2063-2085). IGI Global.

[5] Rossi, R.A. and Ahmed, N.K., 2016. An interactive data repository with visual analytics. ACM SIGKDD Explorations Newsletter, 17(2), pp.37-41.

[6] Roy, B.K., Biswas, S.C. and Mukhopadhyay, P., 2016. Open access repositories for Indian universities: towards a multilingual framework. IASLIC Bulletin, 61(4), pp.150161.

[7] Teredesai, A., Marquardt, J.A., Rizzuto, C.J. and Hughes, T.J., Kensci Inc, 2019. Machine learning model repository. U.S. Patent Application 10/275,710. 